\title{
HPV Vaccines: Current Status
}

\section{Mustafa Erkan SARI ${ }^{1}$, Mehmet Mutlu MEYDANLI ${ }^{1}$}

Ankara, Turkey

\begin{abstract}
Cervical cancer is the fourth most common cancer in women worldwide, and the main cause is Human Papillomavirus infection. Human Papillomavirus vaccines have had dramatic impacts on the prevalence of targeted Human Papillomavirus types $(6,11,16$ and 18), genital warts and precancerous cervical lesions. The World Health Organization and Centers for Disease Control and Prevention have confirmed the safety of Human Papillomavirus vaccines after $>250$ million doses were administered worldwide. World Health Organization approved the two-dose-schedule of Human Papillomavirus vaccines in females younger than 15 years of age, with $\geq 6$ month intervals. Extension of vaccination to men could further reduce the population prevalence of Human Papillomavirus and provide direct protection of men against genital warts and anal, penile and oropharyngeal cancers. Txhe nine-valent Human Papillomavirus vaccine has demonstrated equivalent protection against the four types in the quadrivalent vaccine and high efficacy against the next five commonest causes of cervical cancer (Human Papillomavirus types 31,33,45,52 and 58). The Advisory Committee on Immunization Practices recommends the nine-valent vaccine and it has been approved by the FDA in 2014 for both genders between $11-12$ years of age.
\end{abstract}

Keywords: HPV Vaccines, Efficacy, Nine-valent vaccine

\section{Gynecol Obstet Reprod Med 2017;23(1):54-59}

\section{Introduction}

Cervical cancer is the fourth most common cancer in women worldwide, and the main cause is Human Papillomavirus (HPV) infection. The latest GLOBOCAN data reported an estimated 528.000 new cases and 266.000 deaths due to cervical cancer in 2012 (1). Besides, there were more than 600.000 new cases of HPV-related cancers, including anogenital and oral cancers in both genders. Current estimates indicate that every year 1686 women are diagnosed with cervical cancer and 663 die from the disease in Turkey (2). In 2013 a multicentric retrospective analysis held on 6.388 patients revealed that $25 \%$ of all women with normal and abnormal cytology had HPV infection (3).

\section{${ }^{I}$ Zekai Tahir Burak Women's Health Training and Research Hospital Department of Gynecologic Oncology, Ankara \\ Address of Correspondence: Mehmet Mutlu Meydanll Zekai Tahir Burak Women's Health Training and Research Hospital Department of Gynecologic Oncology Ankara, Turkey mmmeydanli@gmail.com}

Submitted for Publication: $\quad$ 21. 07. 2016 Accepted for Publication: 14.11.2016

\begin{tabular}{|c|c|}
\hline \multicolumn{2}{|c|}{ Access this article online } \\
\hline $\begin{array}{l}\text { Quick Response Code: } \\
\text { a }\end{array}$ & Website: www.gorm.com.tr \\
\hline 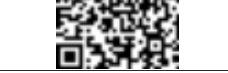 & DOI:10.201613/GORM.2016.620 \\
\hline
\end{tabular}

How to cite this article: Sarl ME. and Meydanl MM. HPV Vaccines: Current Status. Gynecol Obstet Reprod Med 2017;23(1):54-59
In previous studies, deoxyribonucleic acid (DNA) of HPV was detected in the vast majority of patients with cervical dysplasia and carcinoma. Currently, it is considered to be prerequisite for the development of these cervical lesions, but needs a number of supplementary factors for the development invasive carcinoma. There are more than 100 types of HPV identified to be able to infect epithelial cells, but specific types have higher risk for oncogenic transformation. There are 15 high-risk anogenital types; HPV-16 is the most common type, and followed by HPV types $18,45,31,33,35,52$, and 58, whereas HPV types 51, 56, 39, 59, 68, 73, and 66 are much less common.

It is currently believed that there is a step-by-step development of cervical neoplasms; starting with a persistent HPV infection due to a high-risk type, followed by high-grade dysplasia, and finalized in invasive carcinoma. High-risk HPV types can also lead to the development of low-grade intraepithelial lesions (LSIL); however, these lesions substantially regress $(4,5)$.

The discovery of the $15 \mathrm{HPV}$ types which are the most common cause of cervical cancer has risen the idea of whether the development of cervical neoplasia can be prevented by HPV-based screening or primary or secondary prophylaxis with vaccines.

The quadrivalent and bivalent HPV vaccines were introduced in 2006 and 2007, respectively, for the female population. The bivalent vaccine included the most oncogenic HPV types, HPV-16 and HPV-18, which are responsible for $70 \%$ of all cervical cancers worldwide (6). The outer coat (L1) protein, 
a virus-like particle, of these types were introduced into the vaccine in order to prevent cancers of the cervix, vulva, vagina, anus, penis, and oropharynx (7). In addition to HPV-16 and HPV-18, the quadrivalent vaccine also contains L1 proteins of HPV-6 and HPV-11, which are the leading cause of genital warts as well as recurrent respiratory papillomatosis (8). Studies have shown $>90 \%$ efficacy for both vaccines for the prevention of cervical intraepithelial neoplasia (CIN), vulvar intraepithelial neoplasia (VIN), and vaginal intraepithelial neoplasia (VaIN) that were developed due to targeted HPV types, and for quadrivalent vaccine also for the prevention of genital warts (9). The most outrageous finding is that the protection of these vaccines has been observed to continue for at least 10 years based on antibody decay rates in modeling studies (10).

It should be kept in mind that these vaccines are only efficient for the aim of prophylaxis, and therefore not effective in the treatment of existing infections. For this reason, the target population of the vaccines are preadolescent girls that have never had a sexual intercourse. The safety profile in this population was evaluated after approximately 250 million doses of HPV vaccines were administered by the year 2015 worldwide, and no significant side effect was observed $(11,12)$.

\section{Efficacy and Safety}

The efficacy of vaccines can be specified by their effectiveness on decreasing the rates of HPV infection and related diseases.

Markowitz et al. reported that HPV prevalence was reduced to $5.1 \%$ in females between 14 and 19 years from a rate of $11.5 \%$ with the administration of HPV vaccines (13). The vaccine coverage rate in this study was $32 \%$. Similarly, The National Surveys of Sexual Attitudes and Lifestyles from the United Kingdom, in which the coverage rate was $61.5 \%$, revealed the prevalence of HPV-16 and HPV-18 was reduced to $5.8 \%$ in women between $18-20$ years from a rate of $11.3 \%$ (14). A number of other studies also showed the effectiveness of HPV vaccines on decreasing the rate of HPV infections and genital warts. A systemic review of these studies reported that HPV infections and anogenital warts were significantly reduced with the use of HPV vaccine, and also stated that the coverage of the vaccine was $\geq 50 \%$ (15).

An Australian study was the first to report the early results of the effect of a population-based HPV vaccine program on the development of premalignant lesions (16).

In this study, the rates of CIN 2-3 lesions were significantly reduced in females under 18 years of age with the introduction of HPV vaccines. There are four phase III trials in which the clinical efficacy of the HPV vaccine was studied; PATRICIA and Costa Rica trials for the bivalent, and FUTURE I and II trials for the quadrivalent vaccine (17-19). The efficacy of both vaccines was found $96-100 \%$ in terms of preventing HPV 16 and 18-related CIN, carcinoma in situ and cervical cancer. Antibody titers for both vaccines were measured significantly higher than those achieved with natural HPV infection. The duration of these high titers was 5 years in the studies of the quadrivalent vaccine and 8.4 years in the studies of the bivalent vaccine with seropositivity rates of $98.8 \%$ and $100 \%$, respectively. This duration of preventing HPV infection and related disease may be longer when the final results of these studies are reported. However, current data reveals high rates of immunogenicity and adequate duration of protection without any need for a booster dose. The 7-year follow-up of the VIVIANE study revealed that HPV 16-18 vaccine is still successful in protecting women older than 25 years against infections, cytological abnormalities, and lesions associated with HPV 16-18 as well as HPV 31 and HPV 45 (20).

The WHO and CDC have confirmed the safety of HPV vaccines after $>250$ million doses were administered worldwide; however, they have also recommended a much longer duration for detecting whether there would be any adverse events. Although no adverse events were encountered in pregnant women that were inadvertently vaccinated, administration of HPV vaccines in pregnant women is not recommended (21).

\section{Alternative Strategies for Dosing}

The primary dose schedule was held as three doses; at months 0,1 or 2 (for quadrivalent and bivalent, respectively), and 6, and both are currently administered in 3 doses for an optimized immune response. Both HPV vaccines contain viruslike particles which are highly immunogenic. No cut-off value for antibody levels was detected for protection against HPV infection. However, higher titers of antibodies were observed in adolescents than needed which are probably the main reason for higher rates of protection in adult women. With the aim of reducing the cost of vaccination, studies comparing 3-dose schedules to two-dose schedules (in months 0 and 6) were held for both bivalent and quadrivalent vaccines. A number of trials showed equivalent immunogenicity in two-dose schedules in young adolescents compared to three-dose schedules in adult women measured by antibody titers $(22,23)$.

However, memory responses of $\mathrm{T}$ and B-cells were found lower with the two-dose schedule for the quadrivalent vaccine compared to three-dose schedule (24). Besides, although there are no data about the statistical significance, the antibody titers against HPV-18 and HPV-16 were lower after 24 months and 36 months, respectively, in adolescents that underwent twodose schedule compared to the ones that received three doses of vaccination.

The Costa Rica trial was the first to show that two doses, or even one dose, of the bivalent HPV vaccine was successful in the protection against HPV infection $(25,26)$. However, the long-term protection of the HPV vaccine was maintained in all women even they are not seropositive, probably with a similar reason to what is accepted for hepatitis B vaccine $(27,28)$.

In 2014, based on these findings, World Health Organization (WHO) approved the two-dose schedule of HPV 
vaccines in females younger than 15 years of age, with $\geq 6$ month-intervals (29). Since the approval of the WHO Switzerland, Quebec and British Columbia of Canada, the United Kingdom, France, Spain, The Netherlands, South Africa, and Chile have adopted the two-dose schedule. However, while administering the two-dose schedules it is important to consider the relative cost-effectiveness of them, and risk management strategies should be kept under consideration for situations where they do not provide protection for an adequate time (30).

\section{Vaccination of Males}

The first identified HPV-related malignancy is cervical cancer; however, it has been clearly shown that HPV infection can also lead to anogenital, penile and oral cancers as well as anogenital warts in men. One of the main concerns about men is that by the disease load they carry, they can transmit the virus to women by sexual intercourse and thus, they are the indirect cause of the development of cervical cancer in women (31). Anal cancer has a higher risk of development particularly in men that have anal sexual intercourse with men (32). Development of genital warts and recurrent respiratory papillomatosis can also be observed in men. In order to prevent the fore-mentioned diseases, the concept of vaccination in men has arisen. But the main benefit from the vaccination of men would be for the sake of women, because herd protection significantly decreases the rate of the development of HPV infection in women.

Giuliano et al. included 4,065 healthy males between 1626 years of age from 18 countries into a randomized, placebocontrolled, double-blinded trial in which they evaluated the efficacy of quadrivalent HPV vaccine on external genital lesions in men. No males had a history of anogenital warts, penile, perianal or perineal intraepithelial neoplasia or cancer. The efficacy of the vaccine was found $92.4 \%$ and $79 \%$ in 3,463 heterosexual males and in 602 males who had sex with males (MSM), respectively. When the MSM subgroup was evaluated for the primary end point of HPV-6, 11, 16 or 18-related anal intraepithelial neoplasia (AIN) grade 1 (including condyloma), 2 or 3, or anal cancer; the efficacy of the quadrivalent vaccine was found $77.5 \%$, and a median $85 \%$ (range: $76.2 \%$ $100 \%$ ) reduction was observed in the detection of HPV DNA at any time in the post-vaccine follow-up $(33,34)$.

Male vaccination has been found cost-effective in a number of studies, particularly when the achieved coverage of female vaccination remains under $50 \%$. Nevertheless, spending financial resources on female coverage is more rational in order to achieve an actual cost-effective status. (35)

Routine HPV vaccination for males has been recommended since 2011 in the United States; however, as it is not fully funded by the government and is mainly school-based, it did not achieve a coverage as high as in females $(35 \%$ in males vs. $57 \%$ in females) (36).
Another country that recommends HPV vaccination in both genders is Australia. The coverage of male vaccination was no higher than $2 \%$ in 2006; however, it reached a rate of $54 \%$ in 2015 after a government funding was accepted for the program. There is an ongoing trial of HPV vaccination programs for both genders in Alberta and Prince Edward Island of Canada. Besides, an HPV vaccination program for men who have sex with men has been recently planned to be held in the United Kingdom.

\section{Nine-valent HPV vaccine}

As already mentioned, quadrivalent and bivalent vaccines have protection against specific HPV types that are responsible for the development of approximately $70 \%$ of all cervical cancers. Besides these, they also provide cross-protection for a number of other oncogenic types. However, studies on the efficacy and duration of cross-protection have not reported reliable data. With an aim of protection against a higher number of HPV types, the nine-valent vaccine which additionally includes L1 proteins of five other oncogenic HPV types, i.e. 31, $33,45,52$, and 58 , have been introduced with an expectation of protection against approximately $90 \%$ of all cervical cancers (Table 1).

Joura et al. randomized more than 14,000 females between 16 and 26 years to quadrivalent and nine-valent vaccines in a phase III trial in which the primary endpoints were rates of HPV infection and intraepithelial neoplasia (37).

Both vaccines were administered as three doses at months 0,2 and 6 . The overall efficacy of the nine-valent vaccine was found $96.7 \%$, which was higher than the one achieved with the quadrivalent vaccine. The nine-valent vaccine also offered a satisfactory high rate of protection against CIN2 and CIN3, VIN2 and VIN3, and VaIN2 and VaIN3. Moreover, rate of systemic adverse events such as fever and nausea were similar with both vaccines. The only difference was the rate of pain at the injection site which was significantly higher in the ninevalent vaccine arm. It was also reported that antibody titers against HPV-6, 11, 16, and 18 did not decrease in the nine-valent vaccine compared to quadrivalent vaccine.

The Advisory Committee on Immunization Practices (ACIP) recommends the 9-valent vaccine and it has been approved by the FDA in 2014 for both genders between 11-12 years of age (38).

In individuals that were not vaccinated between this target age, catch-up vaccination is recommended until the age of 26 for both genders.

It is not currently recommended to administer an additional nine-valent HPV vaccine after a previous three-dose schedule of the quadrivalent or the bivalent HPV vaccine. However, it is considered safe to administer any kind of HPV vaccine in individuals of both genders that do not know the type of their previous HPV vaccine in an incomplete schedule they previously had. 
Table 1: Characteristics of bivalent, quadrivalent, and nine-valent HPV vaccines (39)

\begin{tabular}{|c|c|c|c|}
\hline & Bivalent & Quadrivalent & 9-valent \\
\hline HPV types included & 16 and 18 & $6,11,16$, and 18 & $6,11,16,18,31,33,45,52$, and 58 \\
\hline Prevented Diseases & $\begin{array}{l}\text { HPV-16 and -18- } \\
\text { related } \\
\text { Cervical cancer } \\
\text { CIN1-3 } \\
\text { AIS }\end{array}$ & 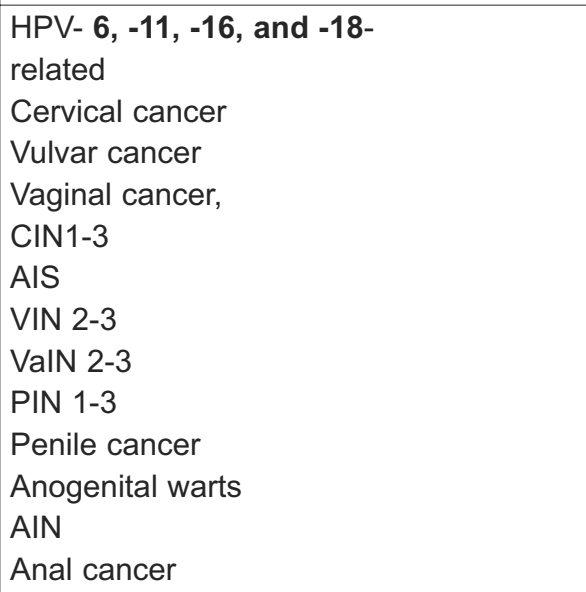 & $\begin{array}{l}\text { HPV-6, }-11,-16,-18,-31,-33,-45 \\
-52, \text { and }-58-\text { related } \\
\text { Cervical cancer } \\
\text { Vulvar cancer } \\
\text { Vaginal cancer } \\
\text { CIN 1-3 } \\
\text { AIS } \\
\text { VIN 2-3 } \\
\text { VaIN 2-3 } \\
\text { PIN 1-3 } \\
\text { Penile cancer } \\
\text { Anogenital warts } \\
\text { AIN } \\
\text { Anal cancer }\end{array}$ \\
\hline Efficacy & $\begin{array}{l}98.1 \% \text { for diseases } \\
\text { related to } \\
\text { HPV } 16 \text { and }-18\end{array}$ & $\begin{array}{l}\text { Approximately } 100 \% \text { for diseases related } \\
\text { to HPV-6, }-11,-16 \text {, and }-18 ; 90.4 \% \text { for } \\
\text { male external genital diseases }\end{array}$ & $\begin{array}{l}>99 \% \text { for diseases related to HPV-6,-11,- } \\
16 \text {,and-18;96.7\% for disease related to } \\
\text { HPV-31, }-33,-45,-52 \text {, and }-58\end{array}$ \\
\hline
\end{tabular}

HPV: Human Papilloma Virus, CIN: Cervical intraepithelial neoplasia, AIS: Adenocarcinoma in situ, VIN: Vulvar intraepithelial neoplasia, ValN: Vaginal intraepithelial neoplasia, PIN: Penile intraepithelial neoplasia, AIN: Anal intraepithelial neoplasia

\section{Conclusion}

The relation between HPV and development of cancer was and has been studied in various molecular and genetic trials as well as it has been shown in epidemiological data and clinical observations. In regard to the younger population it affects and years of life it causes to be lost, the main prophylaxis for cervical cancer is the prophylaxis of HPV. Further studies will enlighten the medical world about the efficacy of HPV vaccines in other HPV-related diseases in males and females. There is a tremendous hope for the development of new dose schedules and new vaccines which will be more efficacious in preventing various HPV-related cancers.

\section{References}

1. Cancer Incidence and Mortality Worldwide: IARC (International Agency for Research on Cancer). Globacan 2012. Estimated cancer incidence, mortality and prevalence worldwide in 2012.

2. Human Papillomavirus and Related Cancers, Fact Sheet 2016. ICO Information Centre on HPV and Cancer (October 7, 2016)

3. Dursun P, Ayhan A, Mutlu L, Çağlar M, Haberal A, Güngör T et al. HPV types in Turkey: Multicenter hospital based evaluation of 6388 patients in Turkish gynecologic oncology group centers. Turk Patoloji Derg 2013;29 (3):210-6.

4. Ho GY, Bierman R, Beardsley L, Chang CJ, Burk RD. Natural history of cervicovaginal papillomavirus infection in young women. N Engl J Med 1998;338(7):423-8.
5. Human papillomavirus testing for triage of women with cytologic evidence of low-grade squamous intraepithelial lesions: Baseline data from a randomized trial. The Atypical Squamous Cells of Undetermined Significance/ Low-Grade Squamous Intraepithelial Lesions Triage Study (ALTS) Group. J Natl Cancer Inst 2000;92(5):397402.

6. Li N, Franceschi S, Howell-Jones R, Snijders PJ, Clifford GM. Human papillomavirus type distribution in 30848 invasive cervical cancers worldwide: variation by geographical region, histological type and year of publication. Int J Cancer 2011;128(4):927-35.

7. Forman D, de Martel C, Lacey CJ, Soerjomataram I, Lortet-Tieulent J, Bruni L et al. Global burden of human papillomavirus and related diseases. Vaccine 2012;20:30 (Suppl 5): F12-F23.

8. Kocjan BJ, Gale N, Hocevar Boltezar I, Seme K, Fujs Komloš K, Hošnjak L et al. Identical human papillomavirus (HPV) genomic variants persist in recurrent respiratory papillomatosis for up to 22 years. J Infect Dis 2013;207(4):583-7.

9. Schiller JT, Castellsague X, Garland SM. A review of clinical trials of human papillomavirus prophylactic vaccines. Vaccine 2012 Nov 20; 30 (Suppl 5): F123-38.

10. David MP, Van Herck K, Hardt K, Tibaldi F, Dubin G, Descamps D et al. Long-term persistence of anti-HPV-16 and -18 antibodies induced by vaccination with the AS04 adjuvant cervical cancer vaccine: modeling of sustained antibody responses. Gynecol Oncol 2009;115 (3 Suppl): S1-6 
11. Macartney KK, Chiu C, Georgousakis M, Brotherton JM. Safety of human papillomavirus vaccines: a review. Drug Saf 2013;36:393-412

12. Arnheim-Dahlstrom L, Pasternak B, Svanstrom H, Sparén P, Hviid A. Autoimmune, neurological, and venous thromboembolic adverse events after immunization of adolescent girls with quadrivalent human papillomavirus vaccine in Denmark and Sweden: cohort study. BMJ 2013; 347:f5906

13. Markowitz LE, Hariri S, Lin C, Dunne EF, Steinau M, McQuillan $\mathrm{G}$ et al. Reduction in human papillomavirus (HPV) prevalence among young women following HPV vaccine introduction in the United States, National Health and Nutrition Examination Surveys. J Infect Dis 2013; 208:385-93.

14. Sonnenberg P, Clifton S, Beddows S, Field N, Soldan K, Tanton $\mathrm{C}$ et al. Prevalence, risk factors, and uptake of interventions for sexually transmitted infections in Britain: findings from the National Surveys of Sexual Attitudes and Lifestyles (Natsal). Lancet 2013;382:1795-806.

15. Drolet M, Benard E, Boily MC, Ali H, Baandrup L, Bauer $\mathrm{H}$ et al. Population-level impact and herd effects following human papillomavirus vaccination programmes: a systematic review and meta-analysis. Lancet Infect Dis 2015; 15(5):565-80

16. Brotherton JM, Fridman M, May CL, Chappell G, Saville AM, Gertig DM. Early effect of the HPV vaccination programme on cervical abnormalities in Victoria, Australia: an ecological study. Lancet 2011;377(9783):2085-92

17. Dillner J. Kjaer SK. Wheeler CM. On behalf of FUTURE I/II Study Group. Four years' efficacy of prophylactic human papillomavirus quadrivalent vaccine against low grade cervical, vulvar, and vaginal intraepithelial neoplasia and anogenital warts: randomized controlled trial BMJ 2010;341:c3493.

18. Paavonen J. Naud P. Salmeron J. Efficacy of human papillomavirus (HPV)-16/18 ASO4-adjuvanted vaccine against cervical infection and pre-cancer caused by oncogenic HPV types (PATRICIA): final analysis of a doubleblind, randomized study in young women. Lancet 2009; 374(9686):301-14.

19. Herrero R. Wacholder S. Rodrigeuz AC. Prevention of persistent human papillomavirus infection by an HPV16/18 vaccine: a community-based randomised clinical trial in Guanacaste, Costa Rica. Cancer Discov 2011; 1(5):408-19.

20. Wheeler CM, Skinner SR, Del Rosario-Raymundo MR, Garland SM, Chatterjee A, Lazcano-Ponce E. et al; VIVIANE Study Group. Efficacy, safety, and immunogenicity of the human papillomavirus 16/18 AS04-adjuvanted vaccine in women older than 25 years: 7-year follow-up of the phase 3, double-blind, randomised controlled VIVIANE study. Lancet Infect Dis 2016;16(10):1154-68.

21. WHO Global Advisory Committee on Vaccine Safety
Statement on the continued safety of HPV vaccination. WHO Weekly Epidemiological Record 14/02/2014.

22. Stanley MA, Sudenga SL, Giuliano AR. Alternative dosage schedules with HPV virus-like particle vaccines. Expert Rev Vaccines 2014;13(8):1027-38

23. Romanowski B, Schwarz TF, Ferguson LM, Ferguson M, Peters K, Dionne $\mathrm{M}$ et al. Immune response to the HPV16/18 AS04-adjuvanted vaccine administered as a 2-dose or 3-dose schedule up to 4 years after vaccination: Results from a randomized study. Hum Vaccin Immunother 2014;10(5):1155-65.

24. Smolen KK, Gelinas L, Franzen L, Dobson S, Dawar M, Ogilvie $\mathrm{G}$ et al. Age of recipient and number of doses differentially impact human B and T cell immune memory responses to HPV vaccination. Vaccine 2012;30(24): 3572-9.

25. Kreimer AR, Rodriguez AC, Hildesheim A, Herrero R, Porras C, Schiffman M et al. CVT Vaccine Group. Proofof-principle evaluation of the efficacy of fewer than three doses of a bivalent HPV16/18 vaccine. J Natl Cancer Inst 2011;103(19):1444-51

26. Safaeian M, Porras C, Pan Y, Kreimer A, Schiller JT, Gonzalez P. et al. CVT Group. Durable antibody responses following one dose of the bivalent human papillomavirus L1 virus-like particle vaccine in the Costa Rica Vaccine Trial. Cancer Prev Res (Philadelphia, PA) 2013;6(11): 1242-50

27. De Carvalho N, Teixeira J, Roteli-Martins CM, Naud P, De Borba P, Zahaf T et al. Sustained efficacy and immunogenicity of the HPV-16/18 AS04-adjuvanted vaccine up to 7.3 years in young adult women. Vaccine 2010; 28:6247-55

28. DeVincenzo R, Conte C, Ricci C, Scambia G, Capelli G. Long-term efficacy and safety of human papillomavirus vaccination. Int J Women's Health 2014;6:999-1010.

29. World Health Organization position paper on HPV vaccines. October 2014. WER 43,89:465-492.

30. Jit M, Brisson M, Laprise JF, Choi Y. Comparing twodose and three-dose human papillomavirus vaccine schedules: cost-effectiveness analysis based on transmission model. BMJ 2015;350: g7584.

31. Palefsky Joel M. Human papillomavirus-related disease in men: not just a women's issue. J Adolesc Health 2010;46 (4 suppl 1): S12-19.

32. Frisch M, Smith E, Grulich A, Johansen C. Cancer in a population-based cohort of men and women in registered homosexual partnerships. Am J Epidemiol 2003;157 (11): 966-72.

33. Giuliano AR, Palefsky JM, Goldstone S, Moreira ED Jr, Penny ME, Aranda $\mathrm{C}$ et al. Efficacy of quadrivalent HPV vaccine against HPV infection and disease in males. $\mathrm{N}$ Engl J Med 2011;364(5):401-11.

34. Palefsky JM, Giuliano AR, Goldstone S, Moreira ED Jr, 
Aranda C, Jessen $\mathrm{H}$ et al. HPV vaccine against anal HPV infection and anal intraepithelial neoplasia. N Engl J Med 2011;365(17):1576-85.

35. Canfell K, Chesson H, Kulasingam SL, Berkhof J, Diaz M, Kim JJ. Modeling preventive strategies against human papillomavirus-related disease in developed countries. Vaccine 2012;30 Suppl 5: F157-67.

36. Stokley S, Jeyarajah J, Yankey D, Cano M, Gee J, Roark $\mathrm{J}$ et al; Immunization Services Division, National Center for Immunization and Respiratory Diseases, CDC.; Centers for Disease Control and Prevention (CDC). Human papillomavirus vaccination coverage among adolescents, 2007-2013, and post licensure vaccine safety monitoring, 2006-2014: United States. MMWR Morbidity and mortality weekly report 2014;63(29):620-24.
37. Joura EA, Giuliano AR, Iversen OE, Bouchard C, Mao C, Mehlsen J et al; Broad Spectrum HPV Vaccine Study. A 9valent HPV vaccine against infection and intraepithelial neoplasia in women. New Engl J Med 2015;372(8):711723.

38. Petrosky E, Bocchini JA Jr, Hariri S, Chesson H, Curtis CR, Saraiya $M$ et al. Use of 9-valent human papillomavirus (HPV) vaccine: updated HPV vaccination recommendations of the advisory committee on immunization practices. Centers for Disease Control and Prevention (CDC). MMWR Morb Mortal Wkly Rep 2015;64(11): $300-4$

39. ACOG-Committee on Adolescent Health Care and Immunisation Expert Work Group. Number 641September 2015 